Check for updates

Cite this: RSC Adv., 2017, 7, 41289

Received 29th March 2017 Accepted 14th July 2017

DOI: $10.1039 / \mathrm{c} 7 \mathrm{ra03648e}$

rsc.li/rsc-advances

\section{Gasochromic properties of novel tungsten oxide thin films compounded with methyltrimethoxysilane (MTMS)}

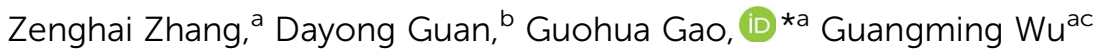 \\ and Haoran Wang ${ }^{a}$
}

Herein, thick tungsten-silicon films with long-term gasochromic performance were synthesized from methyltrimethoxysilane (MTMS) and tungsten oxide sols. Via the addition of MTMS, the thickness of $\mathrm{WO}_{3} / \mathrm{SiO}_{2}$ films was largely increased to nearly $3 \mu \mathrm{m}$ without any cracks. Moreover, the transmittance difference between coloring and bleaching status reached over $97 \%$ in the near-infrared region. Different ratios of $\mathrm{WO}_{3}-\mathrm{MTMS}$ compound films were prepared to confirm that the proper proportion of $\mathrm{WO}_{3}$ : MTMS was $1: 2$, and $\mathrm{WO}_{3}$-TEOS films were also prepared for comparisons. FT-IR and Raman spectra were obtained to characterize the structure of $\mathrm{W}-\mathrm{O}$ and the existence of $-\mathrm{CH}_{3}$ bonds. SEM and TEM images revealed the thickness of compound films and cross-links of the microstructure. The results showed that the $\mathrm{WO}_{3}-$ MTMS films exhibited a stable network with tungsten and silicon bonds, and the methyl group derived from MTMS hydrolysate played a positive role in gel and drying processes.

\section{Introduction}

Tungsten oxide is an important multifunctional material belonging to the n-type oxide semiconductor family and has photocatalytic, photochromic, gasochromic, thermochromic, and electrochromic properties; therefore, tungsten oxide is employed in various applications such as in gas-sensing, information display devices, smart windows, gas sensors, erasable high density storage devices, organic reaction catalysts, and battery cathode materials. ${ }^{1-8}$

For its application in smart windows, the sol-gel method is a very economical way to synthesize large films. Various elements, such as molybdenum, ${ }^{9-12}$ titanium, ${ }^{13,14}$ vanadium, ${ }^{15}$ silicon, ${ }^{16-18}$ and CTAB, are added to tungsten oxide to prepare films. ${ }^{19} \mathrm{WO}_{3}$ compound films with silicon dioxide were mostly fabricated via tetraethoxysilane (TEOS). The structure of the compound exhibited a stable network, and $\mathrm{SiO}_{2}$ (derived from TEOS) restrained the evolution of edge-sharing to cornersharing of $\mathrm{W}-\mathrm{O}-\mathrm{W}$. This compound film had high gas-sensing properties, a rapid coloring-bleaching speed, an excellent transmittance gap, and stable recycling under hydrogen gas in a hydrogen and argon environment. An ordinary glass slide was a relatively good substrate to make films from a $\mathrm{WO}_{3}$-TEOS

${ }^{a}$ Shanghai Key Laboratory of Special Artificial Microstructure, Tongji University, Shanghai 200092, P. R. China. E-mail: gao@tongji.edu.cn

${ }^{b}$ College of Electronic and Information Engineering, Tongji University, Shanghai 200092, P. R. China

'Key Laboratory of Advanced Civil Engineering Materials, Ministry of Education, Tongji University, Shanghai 200092, P. R. China mixed sol. However, to promote the coloring-transmittance depth, thicker films always cracked after many coloringbleaching cycles. ${ }^{17,18}$ Hence, studies are being conducted to solve the issues related with their practical application in smart widows via a sol-gel method.

MTMS has always been used to prepare aerogels with low density and favorable properties of hydrophobicity, ${ }^{20} \mathrm{drag}$ reduction, lipophilicity, and good acoustic performances. ${ }^{21}$ It was thought to be one of general silicon sources, which acted as precursor in aerogel technique filed.

In this study, MTMS was used to provide silicon as the novel precursor to mix tungsten oxide sol in a series of mole ratios. The results showed that compound films had a deep coloringdepth with thicker and non-cracking films. $\mathrm{WO}_{3}-\mathrm{TEOS}$ compound films were also obtained for comparison. FT-IR and Raman spectra were obtained to characterize the organic and inorganic bonds. SEM and TEM images were obtained to determine the surface morphology and the internal structure. UV-visible spectra were obtained to determine the gasochromic properties of the compound films.

\section{Experimental}

\subsection{Preparation of gasochromic films}

$\mathrm{WO}_{3}$ sols were prepared according to the traditional method. About $5 \mathrm{~g}$ of metallic $\mathrm{W}$ powder $(99.8 \%)$ was added to $20 \mathrm{~mL}$ of $\mathrm{H}_{2} \mathrm{O}_{2}(30 \%)$ in EtOH under slow stirring at room temperature under a normal atmosphere. After centrifugation, the solution was subjected to the reflux process $\left(80^{\circ} \mathrm{C}\right)$ until the sol became transparent orange. Under a water cooling system, MTMS was 
added to the $\mathrm{WO}_{3}$ sol under stirring in a mole ratio of $2: 1,1: 1$, $0.9: 1,0.8: 1,0.7: 1,0.6: 1,0.5: 1,0.4: 1,0.3: 1,0.2: 1$, and $0.1: 1$. Then, $\mathrm{PdCl}_{2}$ was added to the mixed sols $\left(\mathrm{WO}_{3}, 0.3 \mathrm{~mol}\right.$ $\mathrm{L}^{-1}$ ) as a catalyst in the $\mathrm{Pd}: \mathrm{W}$ mole ratios of $1: 50$. All films were deposited onto glass slides and polished silicon slides via the dip-coating technique. Samples were kept at $50{ }^{\circ} \mathrm{C}$ for a few minutes to accelerate the volatility of ethanol. UVI was carried out under a high-pressure $\mathrm{Hg}$ lamp (1 kW) for different minutes to make the films stable. The samples were kept under a flow of air during irradiation, and the distance between the films and the light source was $10 \mathrm{~cm}$. Then, the thermal treatment process was carried out in an incubator. Thus, the compound films of $\mathrm{WO}_{3}-\mathrm{MTMS}$ were synthesized. The compound films of $\mathrm{WO}_{3}-$ TEOS were prepared via the similar abovementioned process.

\subsection{Instruments}

All the chemicals used herein were of analytical grade and used without further purification. Tungsten powder (99.9\%), hydrogen peroxide (30\%), EtOH (99.9\%), and TEOS were purchased from the Sinopharm Chemical Reagent Co., Ltd. MTMS was bought from Beijing InnoChem Science \& Technology Co., Ltd.

The structures of the hydrothermal product were characterized by Fourier transform infrared spectroscopy (FT-IR, Tensor27, Bruker Optik Gmbh) and Raman spectroscopy (HORIBA JOBIN YVON HR800). The surface morphology of the nanostructure was obtained by field emission scanning electron microscopy (FESEM, S-4800), transmission electron microscopy (TEM, JEOL-2100), and high-resolution transmission electron microscopy (HRTEM, field emission JEOL-2100). To test the gasochromic properties of the compound films, UV-visible spectra were obtained to determine the properties under hydrogen gas (mixed with argon in a content of 95\%). The transmission measurements of the films at the colored and bleached states were carried out using UV-vis V-570 (Jasco Inc. series spectrometer) at $1000 \mathrm{~nm}$.

\section{Characterization}

FT-IR spectra were obtained to characterize the bond structures of the compound films. Fig. 1 shows the FT-IR spectra of $\mathrm{WO}_{3} /$ MTMS with serial ratios. The absorption peak at $3490 \mathrm{~cm}^{-1}$ was caused by the stretching vibration of $-\mathrm{OH}$, and this peak existed in each sample. The peak at $2970 \mathrm{~cm}^{-1}$ represented the stretching vibration of $-\mathrm{CH}_{3}$ (ref. 22-24) and became sharper as the MTMS content increased. The peaks at 1628 and 1420 were attributed to the bending vibration of $-\mathrm{OH}$ in $\mathrm{H}_{2} \mathrm{O}$ and the $-\mathrm{W}-$ group, respectively. ${ }^{25}$ The band at $1280 \mathrm{~cm}^{-1}$, belonging to methyl deformation, was observed as $\mathrm{Si}-\mathrm{CH}_{3}{ }^{20,24}$ The peak at $1135 \mathrm{~cm}^{-1}$ was considered to be the $-\mathrm{CH}_{3}$ rocking modes of the methoxy group and represented the $\mathrm{Si}-\mathrm{O}-\mathrm{Si}$ bond. ${ }^{\mathbf{2 4 2 6}}$ Peaks at 1039, 900, and $667 \mathrm{~cm}^{-1}$ were assigned as the $\mathrm{C}-\mathrm{O}$ stretching mixed with a small contribution of the Si-O stretching, ${ }^{20,24,27}$ originating from non-hydrolyzed $\mathrm{CH}_{3} \mathrm{Si}\left(\mathrm{OCH}_{3}\right)_{3}$. The peak at $777 \mathrm{~cm}^{-1}$ was the absorption peak of joint action resulting from the stretching vibration of $\mathrm{Si}-\mathrm{C}$ and the rocking vibration of
$-\mathrm{CH}_{3} \cdot{ }^{24}$ The peak at $642 \mathrm{~cm}^{-1}$ was defined as the stretching vibration of the $\mathrm{O}-\mathrm{W}-\mathrm{O}$ in corner-sharing in $\mathrm{WO}_{3}$. The peak at $589 \mathrm{~cm}^{-1}$ corresponded to the stretching vibration of $\mathrm{W}-\mathrm{O}-\mathrm{W}$ in an edge-sharing structure of $\mathrm{W}_{3} \mathrm{O}_{13}$. The peak at $438 \mathrm{~cm}^{-1}$ was considered to be water vibrations in the tungsten oxide structure. ${ }^{7,25,28}$ Traditional references reported that peaks at 960 and $1005 \mathrm{~cm}^{-1}$ were defined as $\mathrm{W}=\mathrm{O}$ terminal stretching, ${ }^{29}$ and 809 and $874 \mathrm{~cm}^{-1}$ corresponded to stretching vibrations of $\mathrm{W}-\mathrm{O}-\mathrm{W}$ in an edge-sharing structure of $\mathrm{W}_{3} \mathrm{O}_{13}$. However, these peaks did not obviously exist. It was speculated that the peak for silicon at $960 \mathrm{~cm}^{-1}$ was covered by the $\mathrm{C}-\mathrm{O}$ stretching mixed with a contribution of the $\mathrm{Si}-\mathrm{O}$ stretching due to the wide range of silicon bonds. Moreover, silicon bonds showed stronger and sharper absorptions with the increasing quantities of silicon in $\mathrm{WO}_{3}-\mathrm{MTMS}$ compound films. In addition, the peaks at 809 and $874 \mathrm{~cm}^{-1}$ were relatively weaker and submerged between the range 777 and $900 \mathrm{~cm}^{-1}$. $^{7}$

Fig. 2 shows the Raman shifts of $\mathrm{WO}_{3}$ and $\mathrm{WO}_{3}-\mathrm{MTMS}$. From Fig. 2(a), basic characteristic peaks of tungsten oxide are shown. The peak at $965 \mathrm{~cm}^{-1}$ was defined as $\mathrm{W}=\mathrm{O}$ terminal stretching, $804 \mathrm{~cm}^{-1}$ belonged to the $\mathrm{W}-\mathrm{O}$ stretching mode, 701 and $264 \mathrm{~cm}^{-1}$ were due to vibrational bonds of $\mathrm{O}-\mathrm{W}-\mathrm{O}$, and a weak peak at $181 \mathrm{~cm}^{-1}$ was considered as the lattice mode of tungsten oxide. As shown in Fig. 2(b), the peak at $1099 \mathrm{~cm}^{-1}$ and the peaks in the range between 714 and $797 \mathrm{~cm}^{-1}$ were considered to be the combined result of stretching and rocking vibrations of $\mathrm{Si}-\mathrm{C}$. The peak near the $960 \mathrm{~cm}^{-1}$ band was defined as a $\mathrm{W}=\mathrm{O}$ terminal stretching peak. The peak at 498 $\mathrm{cm}^{-1}$ was reported as the vibration of $\mathrm{O}-\mathrm{W}-\mathrm{O}, 462 \mathrm{~cm}^{-1}$ was due to water vibration in the $\mathrm{WO}_{3} \cdot 2 \mathrm{H}_{2} \mathrm{O}$ structure, and 249 $\mathrm{cm}^{-1}$ represented the stretching vibration of $\mathrm{W}-\mathrm{O}-\mathrm{W}$. The Pd$\mathrm{Cl}$ characteristic bond was covered by a range of strong peaks for the stretching vibration of $\mathrm{W}-\mathrm{O}-\mathrm{W}$, according to previous studies. ${ }^{7,28,30}$

Fig. 3 shows the fragments of the compound film of $\mathrm{WO}_{3}-$ TEOS. The fragments originated from the cracks of $\mathrm{WO}_{3}-\mathrm{TEOS}$ compound films after coloring-bleaching cycles. On the other hand, Fig. 3(b) shows that the fragment films of $\mathrm{WO}_{3}-\mathrm{TEOS}$

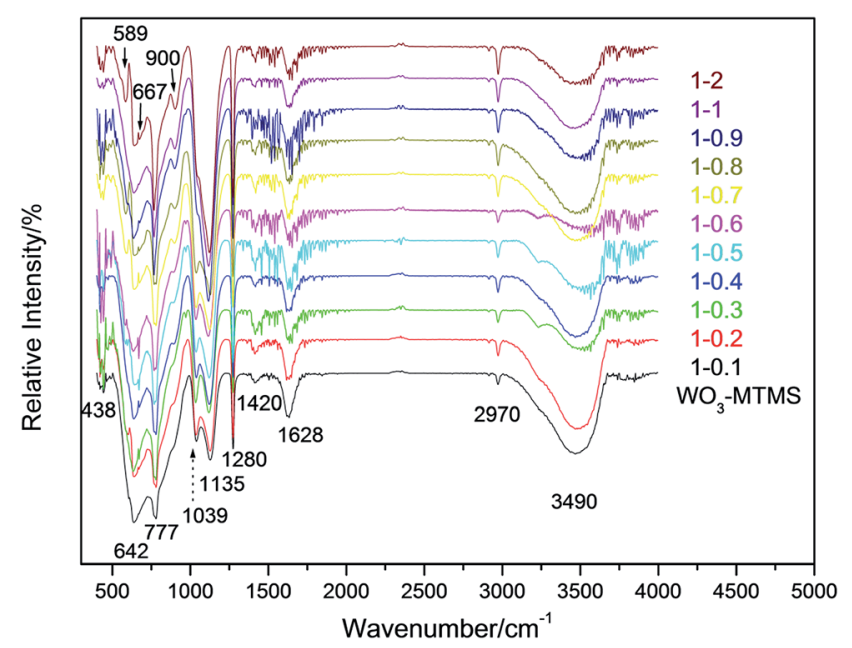

Fig. 1 The FT-IR spectra of $\mathrm{WO}_{3}$ MTMS with different ratios. 

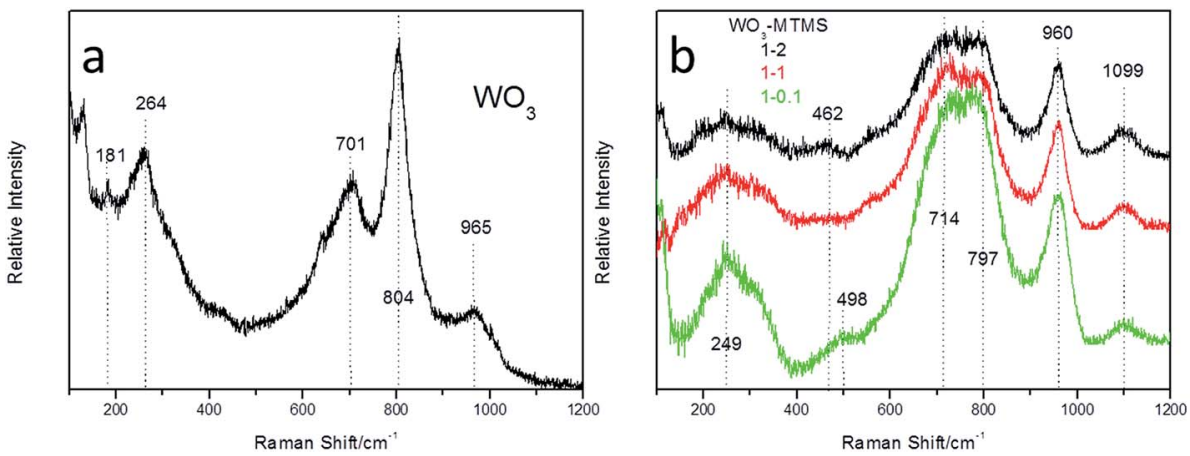

Fig. 2 The Raman shifts of (a) $\mathrm{WO}_{3}$ and (b) $\mathrm{WO}_{3}-\mathrm{MTMS}$ with different ratios.

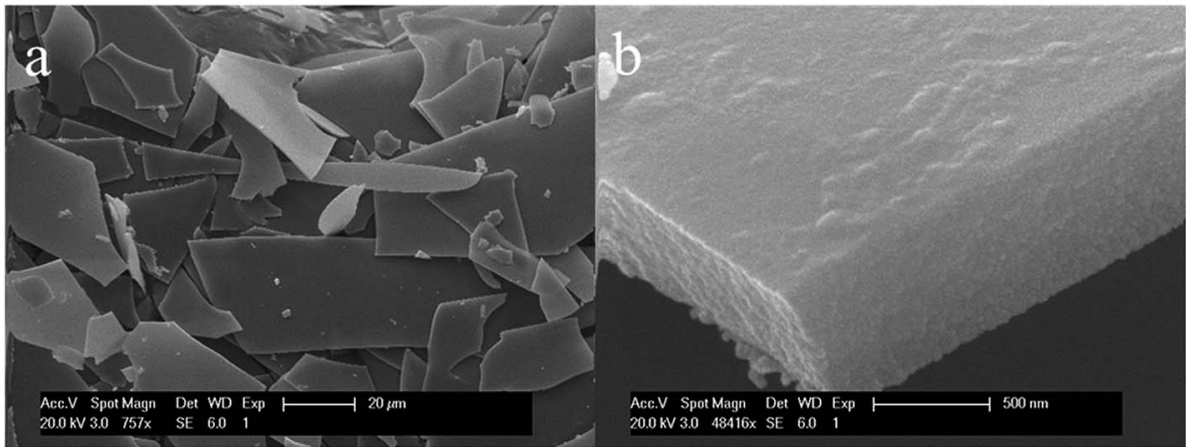

Fig. 3 The SEM image of $\mathrm{WO}_{3}-$ TEOS compound film (a) fragments; and (b) section.

have a relative flat surface and compact composition, and the thickness of the film is nearly $500 \mathrm{~nm}$. The cross-section of the $\mathrm{WO}_{3}$-TEOS film was very smooth and the cut was tidy. In the dip-coating process, $\mathrm{WO}_{3}$-TEOS mixed sols were diluted, and the coating solution was placed on an upward moving glass slide (size of $15 \mathrm{~mm} \times 80 \mathrm{~mm}$ and thickness of $1.2 \mathrm{~mm}$ ) as the substrate, being withdrawn above the top surface of the coating solution. The solvent evaporation concentrated the inorganic species in the entrained solution, and a homogeneous gel film was formed. In this study, the solvent mixture of the coating solution consisted of $\mathrm{WO}_{3}$, TEOS hydrolysate products, ethanol, and a small amount of water. It was expected that most volatile ethanol preferentially evaporated, and then, water evaporated from the entrained solution upon dipping, leaving $\mathrm{WO}_{3}$ and TEOS hydrolysate products. Thus, thin compound films of $\mathrm{WO}_{3}$-TEOS were formed.

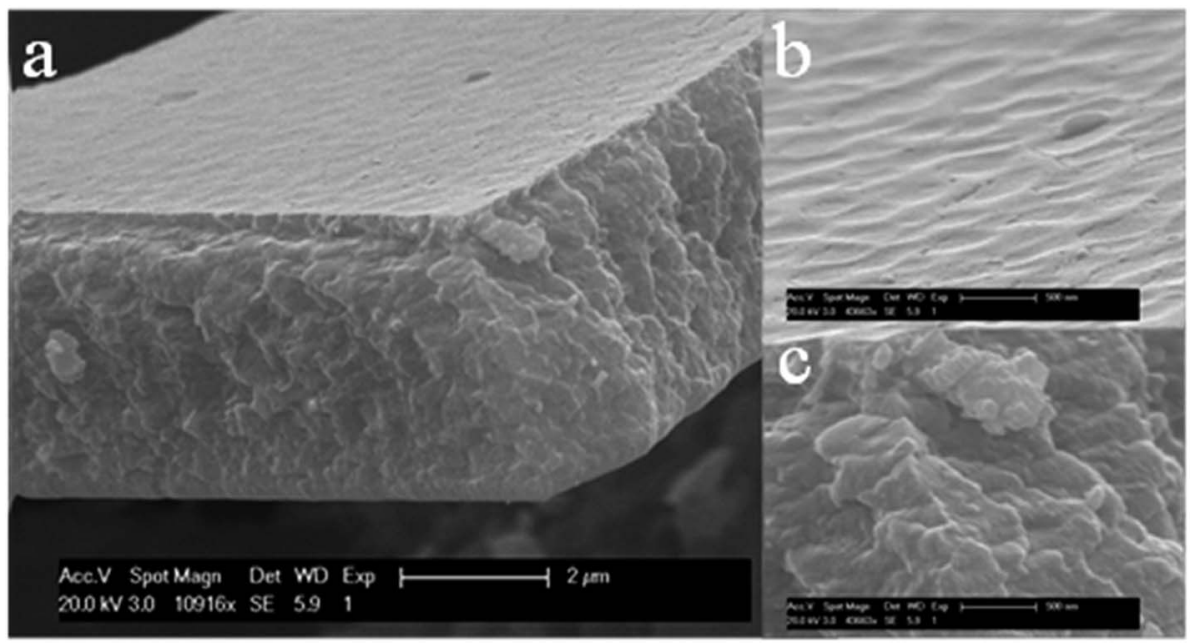

Fig. 4 The SEM image of $\mathrm{WO}_{3}-\mathrm{MTMS}$ compound film (a) in $2 \mu \mathrm{m}$; (b) surface and (c) section. 


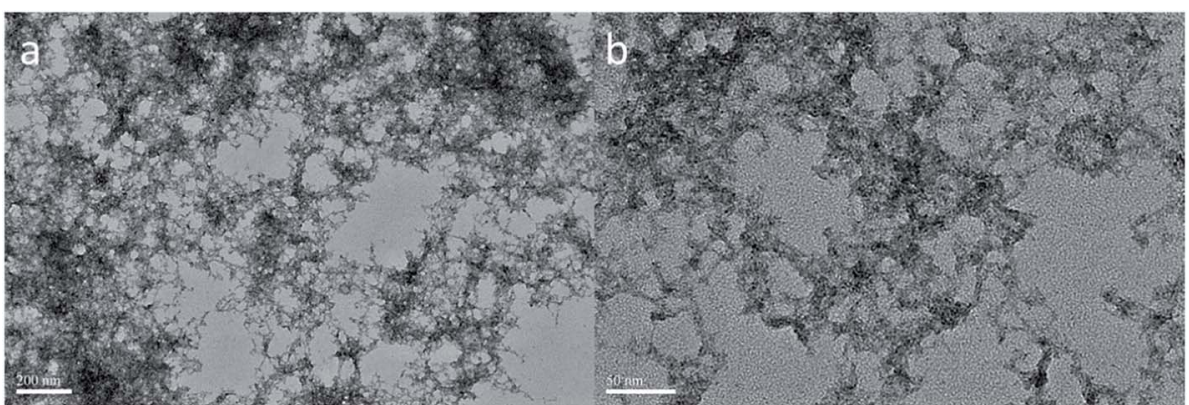

Fig. 5 The TEM image of $\mathrm{WO}_{3}-$ TEOS compound sol at different scales.

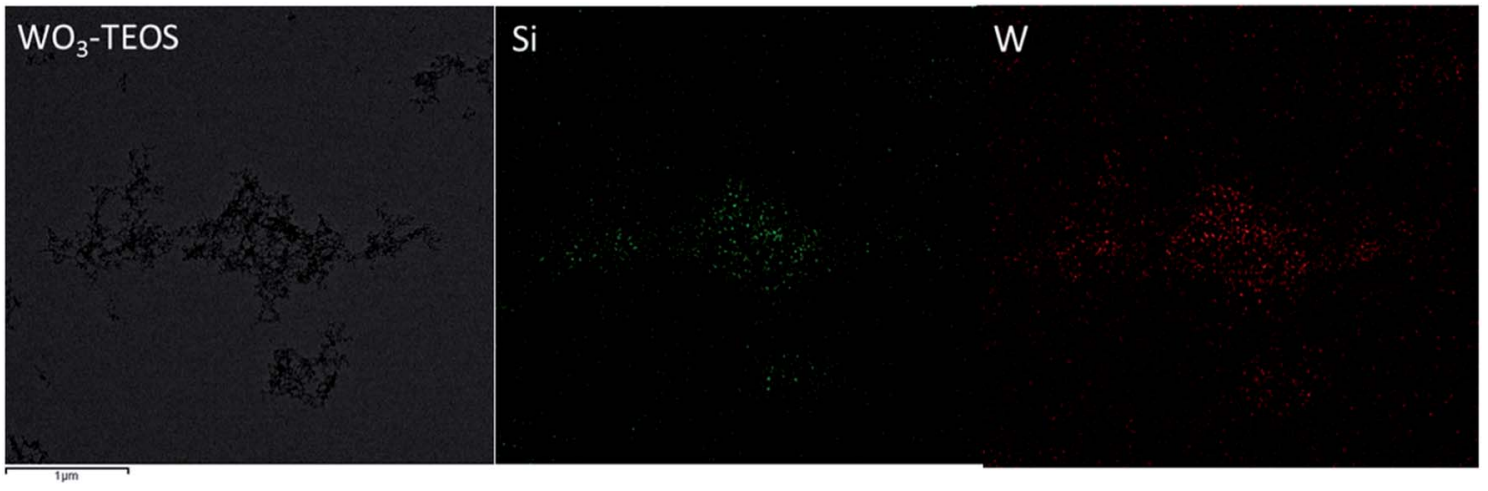

Fig. 6 The TEM image of $\mathrm{WO}_{3}-\mathrm{TEOS}$ and corresponding elemental mapping images of silicon and tungsten.

The compound film of $\mathrm{WO}_{3}$-MTMS had a bumpy surface and a thickness of nearly $3 \mu \mathrm{m}$, as shown in Fig. 4(a) and (b). The concave range was about $300-400 \mathrm{~nm}$ in length. Raised points were linked as shown in Fig. 4(b). In the cross section of Fig. 4(c), it was obviously seen that the small composed grains were reunited to be larger. The concave range was similar to the grain's range. During the stirring time, after MTMS was added to $\mathrm{WO}_{3}$ sol, ice-cooling was necessary to slow down the gel process because MTMS hydrolysis was sensitive to temperature. The mixed sols became sticky even at low temperatures. Sols became stickier as the temperature increased and even gelled to a certain extent. In the dip-coating process, a sticky mixed solution was slowly withdrawn above the top surface of the coating solution. Thus, sticky extent was one possible reason to form thicker films. The temperature requirement of the $\mathrm{WO}_{3}-$
TEOS mixed sol was not as strict as that of $\mathrm{WO}_{3}-\mathrm{MTMS}$ during stirring, which depended on the hydrolysis process and products. The different treatment ways always existed in silicon aerogel preparation.

The morphology of the $\mathrm{WO}_{3}$-TEOS compound sol was determined by TEM. Images showed that an obvious network was chained in the sols, as shown in Fig. 5. The micro-shape of pure the $\mathrm{WO}_{3}$ sol was network-like with thin skeleton structures, and this was basic the requirement to meet hydrogen molecular transmission in gasochromic process. TEOS hydrolyzed under the acidic conditions of $\mathrm{WO}_{3}$, and a cross-linked structure formed with a thicker skeleton than that of $\mathrm{WO}_{3}$. Thus, tungsten and silicon structures crossed each other via bonding. Intersecting gaps of networks came into micro holes to satisfy the diffusion of gas. Layers of networks overlapped

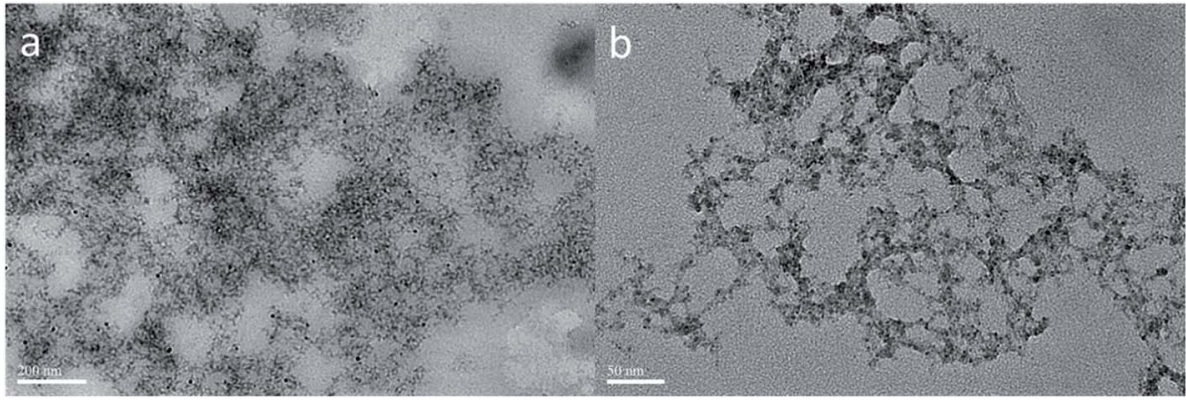

Fig. 7 The TEM image of $\mathrm{WO}_{3}-\mathrm{MTMS}$ compound sol at different scales. 


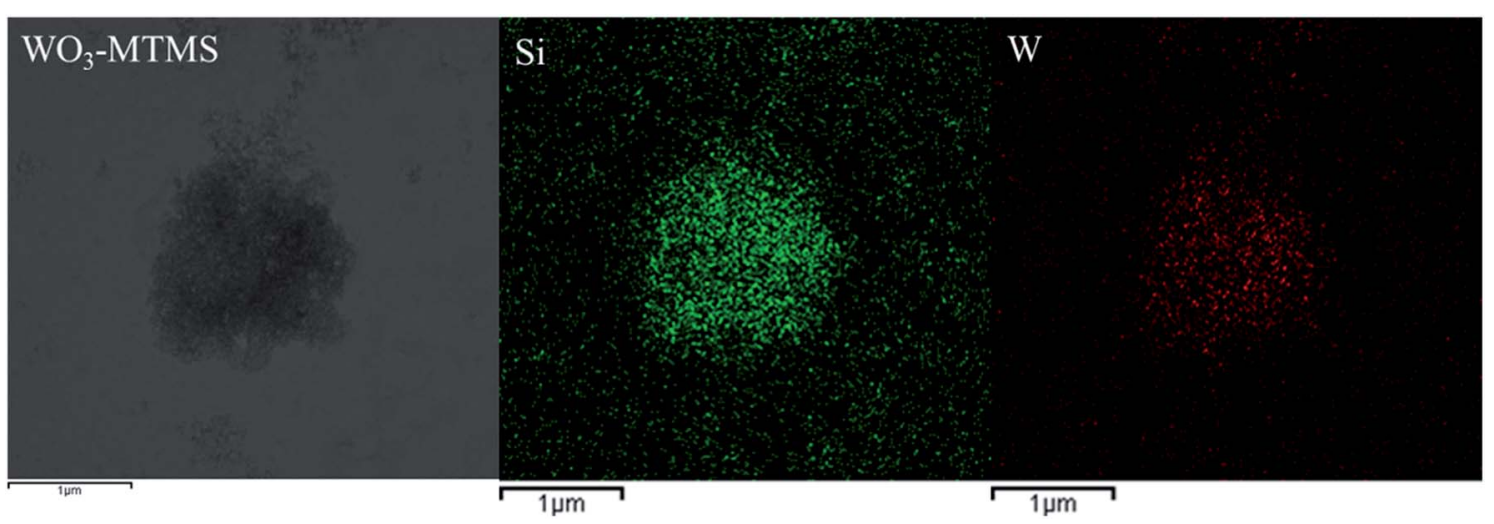

Fig. 8 The TEM image of $\mathrm{WO}_{3}-\mathrm{MTMS}$ and corresponding elemental mapping images of silicon and tungsten.

and formed the entire film, as shown in Fig. 5(a). A similar network was found on a smaller scale, as shown in Fig. 5(b). These results showed that added silicon source dispersed $\mathrm{WO}_{3}$ well and provided a stable structure to $\mathrm{WO}_{3}$.

Silicon and tungsten elements were also uniformly distributed in a network structure (Fig. 6). A selected area of the $\mathrm{WO}_{3}{ }^{-}$ TEOS structure was linked and gathered. Mapping images showed that the compositions of tungsten and silicon were uniformly distributed, which was in agreement with the results shown in Fig. 5.

Fig. 7 shows the TEM image of the $\mathrm{WO}_{3}$ : MTMS compound sol. An obvious network was also formed on a gray area in the sols with a scale of $200 \mathrm{~nm}$. The hydrolysis speed of MTMS under the acid conditions of $\mathrm{WO}_{3}$ was faster, and the reaction was more violent than that of TEOS in $\mathrm{WO}_{3}$. Therefore, icecooling was needed, and sticky sols were obtained. A crosslinked structure formed with a thicker skeleton than that of $\mathrm{WO}_{3}$-TEOS, as shown in Fig. 7(a). The network was attached to the gray area, and the thickness of gray substrates was inhomogeneous. Fig. 7(b) shows a thinner network skeleton on a smaller scale. Compared to Fig. 5(b), herein, the micro- skeleton structure of $\mathrm{WO}_{3}$-MTMS was more uniform than that of $\mathrm{WO}_{3}$-TEOS. As one kind of silicon precursor, MTMS hydrolysis products maintained well-linked silicon shapes. Thus, tungsten and silicon links crossed each other and formed more stable structures.

To identify the elements of the network, mapping images, as shown in Fig. 8, were obtained for the circular area shown in Fig. 7. Silicon and tungsten elements were uniformly distributed in the network structures and also in dispersed surroundings. Besides the circular area, silicon and tungsten compositions were also seen, which demonstrated that there were silicon elements in the abovementioned gray area.

\section{Gasochromic properties}

$\mathrm{WO}_{3}$, with a catalyst film, had a good performance in gasochromics as an excellent semiconductor material. However, gasochromic properties require a coloring-bleaching response, coloring transmittance depth, and cycle durability. Fig. 9 shows the gasochromic properties of $\mathrm{WO}_{3}$ with a catalyst under the wavelength of $1000 \mathrm{~nm}$ via the UV spectra. The coloring-
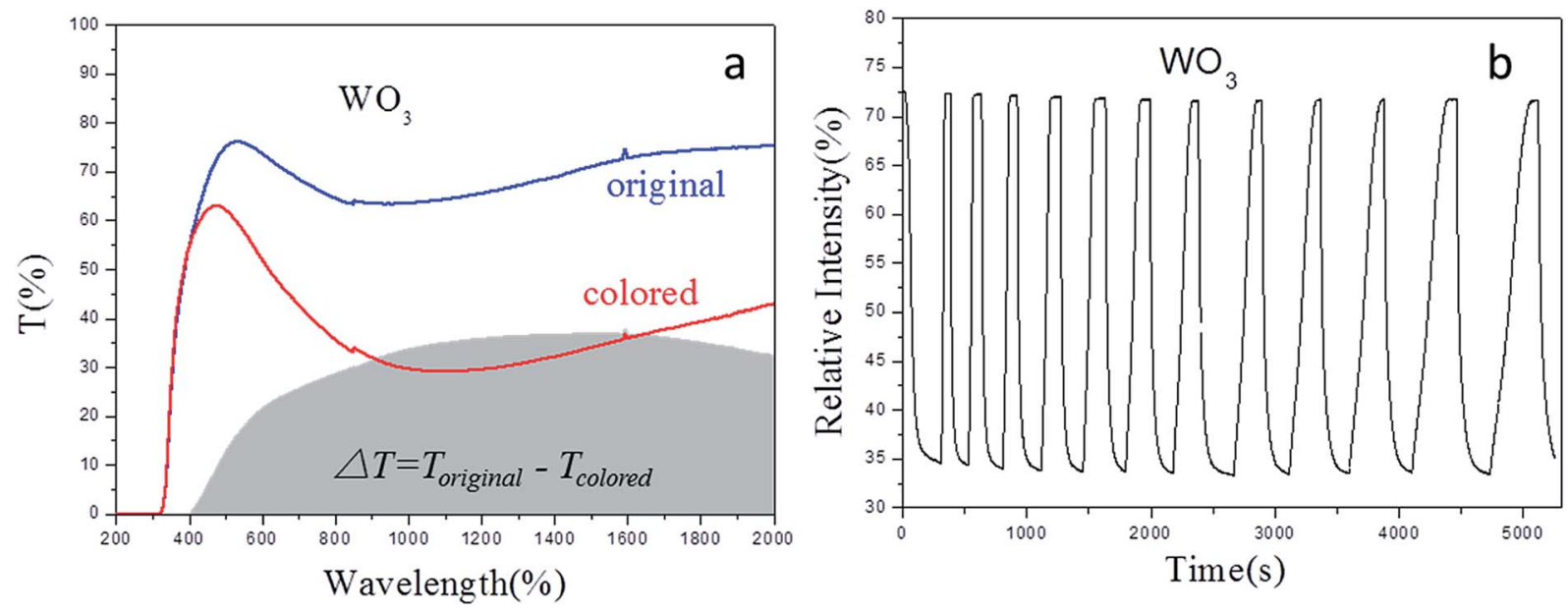

Fig. 9 Gasochromic properties of compound films of $\mathrm{WO}_{3}$ (a) full wavelength transmission in original and colored states; (b) cycles of coloringbleaching. 

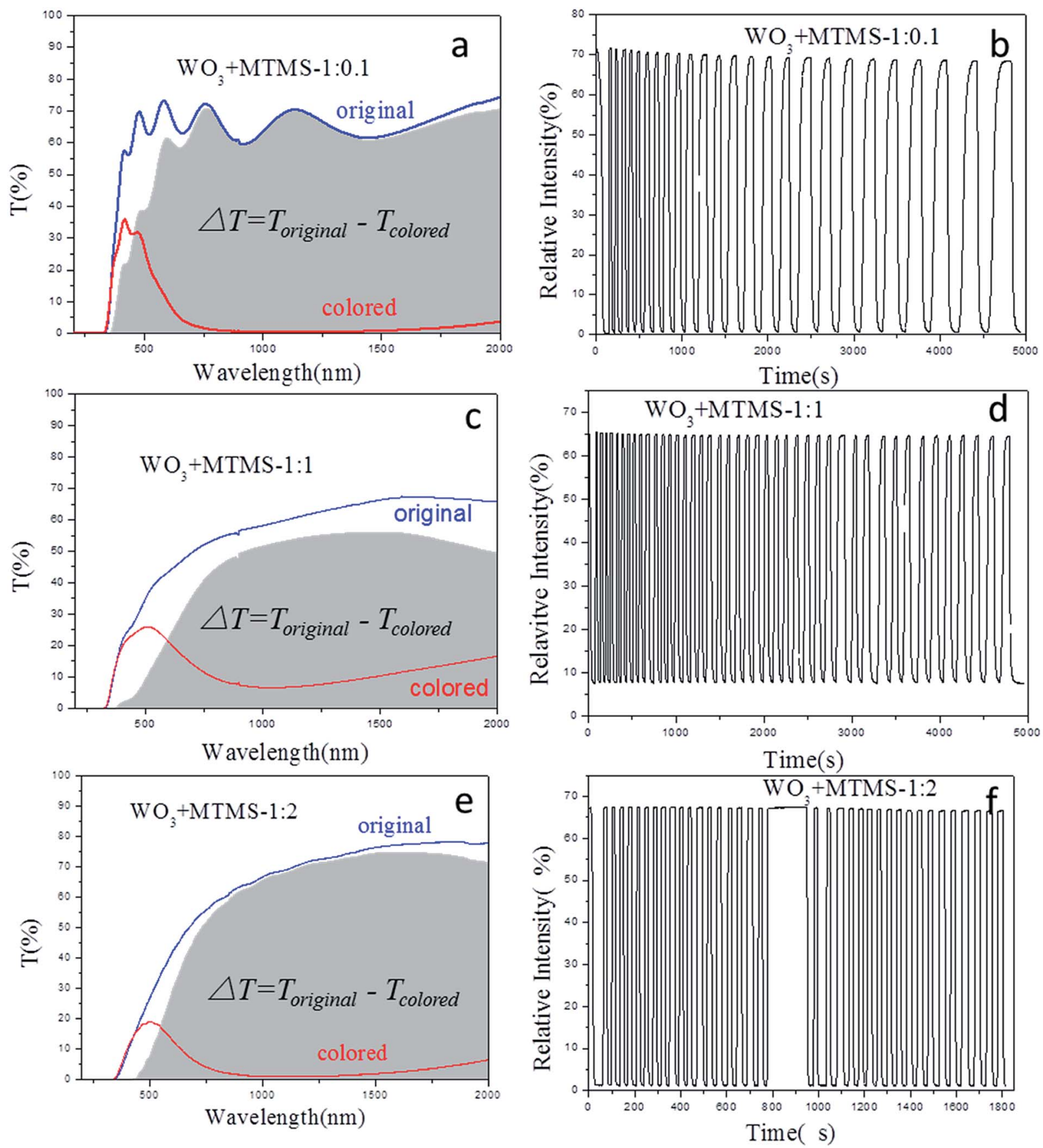

Fig. 10 Gasochromic properties of compound films of $\mathrm{WO}_{3}-\mathrm{MTMS}$ at different ratios: (a), (c), and (e) full wavelength transmission in original and colored states; (b), (d), and (f) cycles of coloring-bleaching.

bleaching response time depended on the catalyst, microstructure, bonding structure, and so on. ${ }^{4,7,9,18}$ The significant property index was coloring transmittance depth, and thicken the film was a solution to increase the depth gap. However, the durability of coloring-bleaching cycles was not good, as shown in Fig. 9(a). It was seen that the coloring and bleaching speed (transmittance change) became lower over time, as shown in Fig. 9(b). As abovementioned, pure $\mathrm{WO}_{3}$ films were thin skeleton structures, and the path of hydrogen gas was always blocked. In recent years, $\mathrm{WO}_{3}$-based compound films have been studied.
Fig. 10 shows the gasochromic properties of the compound films with series ratio under the same conditions as those of the $\mathrm{WO}_{3}$ film. As Fig. 10(a) and (b) showed, they were the full length transmittance and time-responding properties of $\mathrm{WO}_{3}-\mathrm{MTMS}$ compound film with the ratio $1: 0.1$. The transmittance in the original state was about $60 \%$ with the light source at $1000 \mathrm{~nm}$ (the baseline correction was $100 \%$ in air). However, the colored state was nearly $0 \%$. It was caused by the addition of MTMS to increase the film depth. The cycling was not stable, and the coloring-bleaching speed obviously reduced. Fig. 10(c) and (d) 

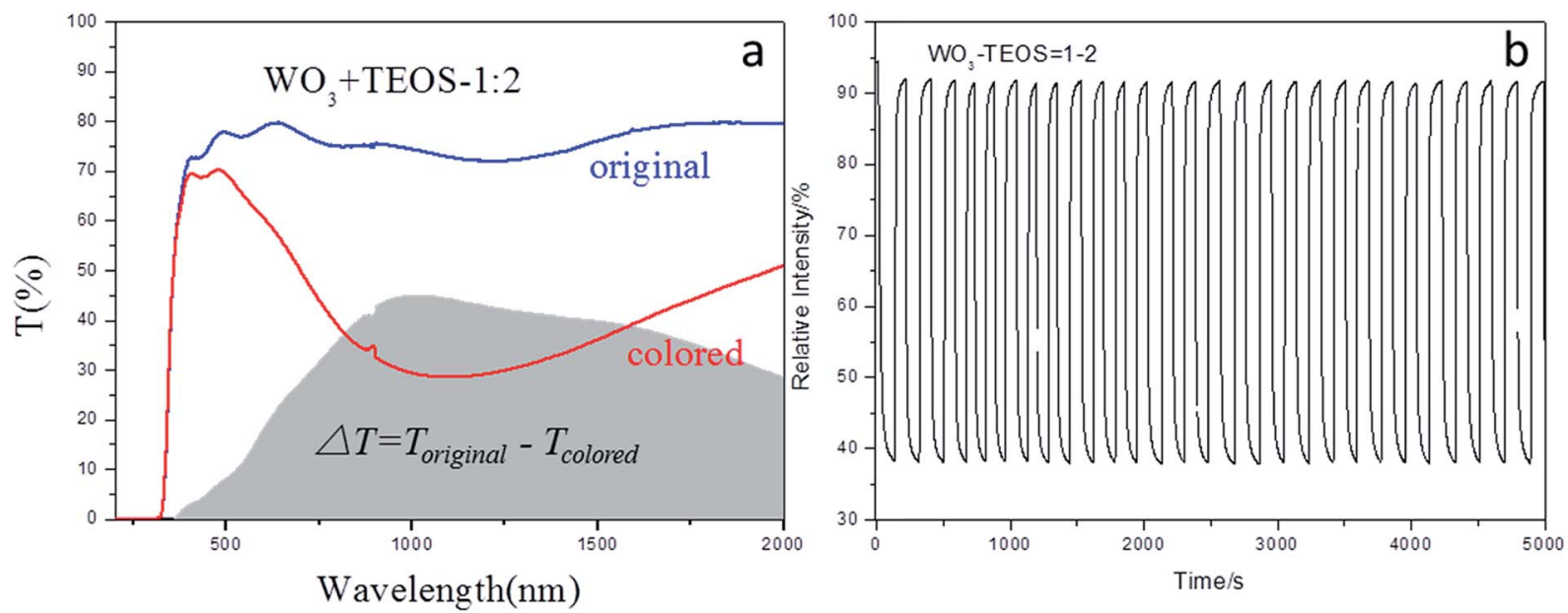

Fig. 11 Gasochromic properties of compound films of $\mathrm{WO}_{3}-\mathrm{TEOS}$ (a) full wavelength transmission in original and colored states; (b) cycles of coloring-bleaching.

show the gasochromic property of the $\mathrm{WO}_{3}$-MTMS compound film with the ratio $1: 1$. Transmittance states were different from the ratio of $1: 0.1$ as shown in Fig. 10(c). The transmittance of the original state increased as the wavelength increased, but the colored state maintained a peak at nearly $500 \mathrm{~nm}$. The transmittance between 900 and $1200 \mathrm{~nm}$ was lower than $2 \%$. Fig. 10(d) shows the time-response of the coloring-bleaching process for the $\mathrm{WO}_{3}$-MTMS compound film with the ratio $1: 1$. The original and bleaching transmittance was about $65 \%$. The stable colored state transmittance reached $8 \%$. The number of cycles was 24 in $5000 \mathrm{~s}$. The latter part in Fig. 10(d) shows the reduction of coloringbleaching speed. Fig. $10(\mathrm{e})$ and (f) show the properties of $\mathrm{WO}_{3^{-}}$ MTMS at a ratio of $1: 2$. The original transmittance was about $67.5 \%$. The first hydrogen-sensing reaction was fast in $2-5 \mathrm{~s}$ with the transmittance reaching $2 \%$. The bleaching transmittance change was $65 \%$ up in 1-2 s, and the state showed a static recycle. The coloring depth was nearly $97 \%$, compared the original state to coloring state of the film. The increase of MTMS amount acted more advanced properties of gasochromics including stable coloring-bleaching cycles and coloring depth.

As a comparison, the $\mathrm{WO}_{3}$-TEOS compound film was synthesized to determine the gasochromic property, as shown in Fig. 11. The transmittance gap achieved was $45 \%$, and the coloring-bleaching cycle number was more than 30 in $5000 \mathrm{~s}$. There was no obvious reduction in the coloring-bleaching speed and circulation stability; this showed that the addition of TEOS provided effective $\mathrm{SiO}_{2}$ constituent and strengthen gasochromic property of $\mathrm{WO}_{3}$-based films.

\section{Discussion}

At room temperature, hydrolysis of MTMS can lead to the quick formation of its gel. Thus, MTMS was kept at low temperatures, as stated in part 2.1. MTMS is an outstanding precursor to synthesize, but it is not conductive to form a uniform film. The $\mathrm{WO}_{3}$-MTMS compound films were thicker, based on several evidences. The raw solution of MTMS was oil-like and hydrolyzed violently. Then, the viscosity of sol was increased. After the general dip-coating process, a thick homogeneous gel film was synthesized. As shown in Fig. 12, the schematic explains the formation of $\mathrm{WO}_{3}$-MTMS. Cross-linked structures of $\mathrm{WO}_{3}{ }^{-}$ MTMS were dispersed by ethanol, and the widths could be kept between 20 and $30 \mathrm{~nm}$. Links of $\mathrm{WO}_{3}-\mathrm{MTMS}$ became clusters during drying. Thus, stable, thick films were synthesized.

The significant difference between $\mathrm{WO}_{3}-\mathrm{MTMS}$ and $\mathrm{WO}_{3}-$ TEOS was the presence of a methyl group. Anti-reflective membranes are usually made using TEOS as a precursor. The ammonization process was needed to increase methyl groups to enhance the hydrophobic properties.

TEOS was a silicon source that supported the microstructure to promote the $\mathrm{WO}_{3}$-based film in coloring-bleaching response and cycles. Hundreds of cycles were achieved, and the colored transmittance reached more than $50 \%$, but with serious cracking. Due to the nanoscale size and large specific surface area, nanochains contained many polarized hydroxyls on their surfaces and exhibited high activity for the TEOS hydrolysis. In
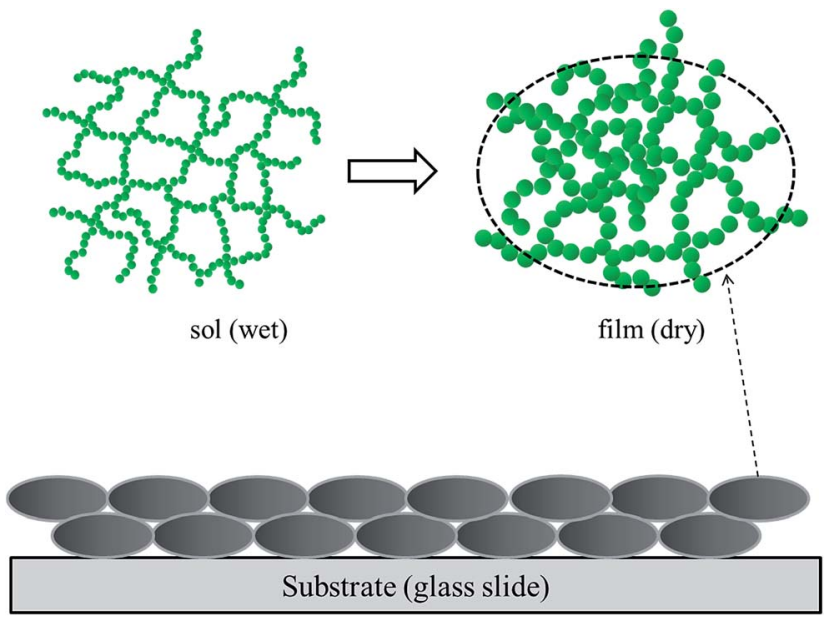

Fig. 12 Schematic of $\mathrm{WO}_{3}-\mathrm{MTMS}$ compound films. 
addition, these active polarized hydroxyls and ethanol vapor molecules would incorporate easily, thus producing a highly compressive capillary stress within the nanochains. During the drying process, ethanol volatized and caused the film to shrink. Heating accelerated the reduction of hydroxyls, and shrinkage became evident. Moreover, heat treatment would produce considerable thermal expansion from the solid substrate, and the expansion would supply sol-gel coating a gradient strain, which gradually decreased from the substrate to the coating surface. $^{31}$ The gasochromic process is a redox reaction to produce $\mathrm{H}_{2} \mathrm{O}$. MTMS provided a methyl group to balance $-\mathrm{OH}$ in the film structures and restrain the shrinkage of the film. The films without any cracking were formed.

MTMS and TEOS were precursor choices to prepare a silicon aerogel. The structure of the silicon skeleton assisted $\mathrm{WO}_{3}$ to form a special network, and provided fluent paths to hydrogen gas. Water produced via the coloring-bleaching process could be driven from internal. Hence, the compound films of $\mathrm{WO}_{3}-$ MTMS acted as well as $\mathrm{WO}_{3}-$ TEOS.

During the experiments, it was found that the mixed sol of $\mathrm{WO}_{3}-\mathrm{MTMS}$ had a good film-forming ability on B270, which was one kind of silicon substrate, but the latter could only form a film on ordinary glass slides. The organic bonds existing on $\mathrm{Si}-\mathrm{CH}_{3}$, which is non-hydrolyzable, and raiment could stick on the surface of $\mathrm{B} 270$, but the $\mathrm{WO}_{3}$-TEOS could not act well. Because of the methyl group, the films were thicker, and the transmittance of bleaching status was lower than that of $\mathrm{WO}_{3}$-TEOS.

\section{Conclusions}

The study introduced a novel silicon source to mix $\mathrm{WO}_{3}$ sols, and the compound films displayed excellent gasochromic properties in coloring-bleaching recycling with a deep coloringdepth rate of $97 \%$. The compound films were thick $(3 \mu \mathrm{m})$ with no-cracking. FT-IR showed the existence of $-\mathrm{CH}_{3}$, which was derived from the MTMS-hydrolyzed products. Raman spectra demonstrated the intrinsic peaks of tungsten oxide and silicon oxide. Element analysis revealed that tungsten and silicon were homogeneously distributed. Due to the reaction conditions and hydrolysis properties of MTMS, the film was thicker and lower original transmittance difference than $\mathrm{WO}_{3}$-TEOS. Existence of methyl groups restricted the film shrinkage caused by $-\mathrm{OH}$, and the films acted no-cracking. The outstanding properties of $\mathrm{WO}_{3}-\mathrm{MTMS}$ broadened the attacking substrate choices such as B270.

\section{Acknowledgements}

The authors gratefully acknowledge the financial support received from the Fundamental Research Funds for the Central Universities, the Shanghai Committee of Science and Technology (13JC1408700) and the National Natural Science Foundation of China (51472182, 51272179, 11404213 and U1503292).

\section{References}

1 H. Yuping, W. Zhenyu, et al., Chem. Mater., 2003, 15, 4039.
2 S. M. A. Durrani and E. E. Khawaja, Sol. Energy Mater. Sol. Cells, 2002, 71, 313.

3 M. A. Habib and S. P. Maheswarf, J. Appl. Electrochem., 1993, 23, 44.

4 A. Georg, W. Graf, R. Neumann, et al., Sol. Energy Mater. Sol. Cells, 2000, 63, 165.

5 S. J. Ippolito and S. Kandasamy, Sens. Actuators, B, 2005, 108, 154. 6 Y. Miseki and H. Kusama, J. Phys. Chem. Lett., 2010, 1, 1196.

7 A. Georg, W. Graf, R. Neumann and V. Wittwer, Solid State Ionics, 2000, 127, 319-328.

8 H. A. Therese, J. Li, U. Kolbb and W. Tremel, Solid State Sci., $2005,7,67$.

9 K. A. Gesheva, T. Ivanova, B. Marsen, B. Cole, E. L. Miller and F. Hamelmann, Surf. Coat. Technol., 2007, 201, 9378.

10 F. Paraguay-Delgado, Y. Verde, E. Cizniega, J. A. Lumbreras and G. Alonso-Nuñez, J. Nanosci. Nanotechnol., 2008, 8, 6445.

11 T. Ivanova, K. A. Gesheva, M. Kalitzova, F. Hamelmann, F. Luekermann and U. Heinzmann, J. Optoelectron. Adv. M., 2009, 11, 1513.

12 Z. Zhang, G. Wu, G. Gao, J. Wu and W. Feng, Proc. SPIE, 2010, 7995, 799510.

13 B. Orel, U. Lavrencicstangar, M. G. Hutchins, et al., J. NonCryst. Solids, 1994, 175, 251.

14 F. Wei, G. M. Wu, G. H. Gao, Z. H. Zhang, J. D. Wu and X. W. Zhou, Rare Met. Mater. Eng., 2012, 41(S3), 627.

15 C. Zhao, H. Tao, F. Peng, R. Pan and X. Zhao, J. Sol-Gel Sci. Technol., 2016, 78, 582.

16 D. Saygin-Hinczewski, M. Hinczewski, I. Sorar, F. Z. Tepehan and G. G. Tepehan, Sol. Energy Mater. Sol. Cells, 2008, 92, 821.

17 F. Wei, Wu G. ming, G. Guohua and Z. Zenghai, Chin. J. Vac. Sci. Technol., 2012, 8, 688.

18 G. Gao, J. Wu, G. Wu, Z. Zhang, W. Feng, J. Shen and B. Zhou, Sens. Actuators, B, 2012, 171-172, 1288.

19 H. Kaper, I. Djerdj, S. Gross, H. Amenitsch, M. Antoniettia and B. M. Smarsly, Phys. Chem. Chem. Phys., 2015, 17, 18138.

20 S. Yun, H. Luo and Y. Gao, RSC Adv. , 2014, 4, 4535.

21 P. Yan, B. Zhou and A. Du, RSC Adv., 2014, 4, 58252.

22 T. F. Tenisheva, A. N. Lazarevl and R. I. Uspenskaya, J. Mol. Struct., 1977, 37, 173.

23 B. Orel, U. Opara Krasovec and N. Groselj, J. Sol-Gel Sci. Technol., 1999, 14, 291.

24 M. Montejo, F. Partal Urena, F. Márquez, I. S. Ignatyev and J. J. Lopez Gonzalez, J. Mol. Struct., 2005, 744-747, 331-338.

25 M. F. Daniel, B. Desbat and J. C. Lassegues, J. Solid State Chem., 1987, 67, 235-247.

26 S. D. Bhagat, C.-S. Oh, Y.-H. Kim, Y.-S. Ahn and J.-G. Yeo, Microporous Mesoporous Mater., 2007, 100, 350-355.

27 N. Boris Orel, U. Groselj, O. Krasovec and R. Jese, J. Sol-Gel Sci. Technol., 2002, 24, 5-22.

28 U. Opara Krasovec, B. Orel, A. Georg and V. Wittwer, Sol. Energy, 2000, 68(6), 541-551.

29 M. Zayat, R. Reisfeld and H. Minti, J. Sol-Gel Sci. Technol., 1998, 11, 161-168.

30 B. Orel, N. Groselj, U. Opara Krasovec, M. Gabrscek, P. Bukovec and R. Reisfeld, Sens. Actuators, B, 1998, 50, 234-245.

31 S. Kumon, K. Nakanishi and K. Hirao, J. Sol-Gel Sci. Technol., 2000, 19, 553-557. 